\title{
Physicians' perception about electronic medical record system in Makkah Region, Saudi Arabia
}

\author{
Hani Abdulsattar Shaker, Mian Usman Farooq, Khalid Obeid Dhafar \\ Directorate General of Health Affairs Makkah Region, Makkah, Saudi Arabia
}

\begin{tabular}{|c|}
\hline Access this article online \\
\hline Website: www.avicennajmed.com \\
\hline DOI: 10.4103/2231-0770.148499 \\
\hline Quick Response Code: \\
$\square$ \\
\hline
\end{tabular}

\section{ABSTRACT}

Objectives: The study was done to determine the physicians' perception about electronic medical record system (EMRS) in the context of its productivity in order to improve its functionality and advantages. Materials and Methods: This cross-sectional survey was performed from July to August 2009 with structured questionnaire of 15 closed-ended questions with five points Likert scaling starting from strongly disagree to strongly agree as $1-5$, reflecting the perception of physicians about EMRS. The physicians of the Makkah region working in six different hospitals were selected. "Positive" response means if percent of responses were rated 4 or 5 (agree/strongly agree), "neutral" if rated 3 , and negative if rated 1 or 2 (strongly disagree/disagree). Descriptive data analysis techniques were used. Results: We selected 317 completed questionnaires. Majority of subjects were from King Fahd Hospital, Jeddah (83, $26.3 \%)$, residents $(147,46.4 \%)$, male $(200,63.1 \%)$, expatriates $(207,65 \%)$, and age group $36-45$ years $(133,42 \%)$ were dominant. The stem regarding importance of computers for practicing medicine and EMRS to improve quality of practice was appreciated by majority, that is, 77.7 and $71.2 \%$, respectively. However, "It does not disrupt the workflow" (35.1\%) and "EMRS is comfortable while entering the data instead of writing" (34.8\%) were appreciated negatively. Consultants (53.9\%), male (53.4\%), expatriates $(56.7 \%)$, physicians of King Abdul Aziz Hospital, Ta'if (56.9\%), and age group of 46-55 years (53.8\%) appreciated EMRS positively. Overall perception of EMRS was found positive by $52.8 \%$. Conclusion: Majority appreciated the EMRS, but specific concerns about its usage easiness and workflow disturbance were opposed by them also.

Key words: Computer, cross-sectional survey, electronic medical record system, physicians

\section{INTRODUCTION}

Most of the Ministry of Health (MOH) hospitals in Saudi Arabia, adapted a separate local Health Information System that reflect the Saudi government efforts of implementing advanced information and communication technology in healthcare sectors. ${ }^{[1]}$ General Directorate of Health Affairs, Makkah region is considered as the largest health region directorate of $\mathrm{MOH}$ in Saudi Arabia managing 36 hospitals all over the four cities (Makkah, Jeddah, Ta'if, and Qunfuthah). ${ }^{[2]}$ At the time of study, nine out of $36 \mathrm{MOH}$ governed hospitals had acquired electronic medical record system (EMRS), but six hospitals were using EMRS for an average of 5 years, that is, three in Jeddah used Oasis system; two in Makkah, that is, Alnoor Specialist Hospital used Care Ware system; while Hera General Hospital used Arabian Computer Services system. One hospital in Ta'if district used iCare system. Each system has all the basic and specific EMRS key functions.

Saudi Arabia has prioritized the development of e-Health as well as the transition from paper-based health record to electronic health record. The Saudi government adopted the following mission for e-Health: "A safe quality healthcare system based on patient centric care guided by standards, enabled by e-Health". ${ }^{[3]}$ The $\mathrm{MOH}$ allocated a total of 4 billion Saudi riyals towards e-Health programs for the 4-year period from 2008 to 2011. An e-Health plan integrates with the plans of the $\mathrm{MOH} .^{[4]}$ 
Studies on EMRS uptake in Saudi Arabia have been found scarce, but EMRS use has been prioritized by the Saudi government, so it is important that its perception be measured by end users, especially the physicians. The primary objective of the study is to determine the physicians' perception about EMRS in the context of its productivity in $\mathrm{MOH}$ hospitals in Makkah region, Saudi Arabia, in order to improve its functionality and advantages.

\section{MATERIALS AND METHODS}

The physicians working in six government hospitals $(\mathrm{MOH}$, Saudi Arabia) having EMRS since the duration of at least 1 year underwent a cross-sectional survey during July-August 2009. Hera General Hospital (H1), Makkah city, (317 beds); King Abdul Aziz Hospital (H2), Ta’if city, (691 beds); King Fahd Hospital (H3), Jeddah city, (840 beds); Maternity and Child Health Hospital (H4), Jeddah city, (390 beds); Alnoor Specialist Hospital (H5), Makkah city, (627 beds); and King Abdul Aziz Hospital (H6), Jeddah city, (559 beds) have been selected. Physicians who were in direct contact with patients comprised the study population.

Sample size $(n)$ determination was done by following formula as 317 out of total study population $(P)$ size, that is, 1,802 , by keeping the margin of error (D) $5 \%$, confidence level of $95 \%$, response distribution $(P)$ of $50 \%$ and response rate $(\mathrm{RR})$ of $100 \%$. Sample Size $=n /[1+(n /$ population $)]$. In which $n=\mathrm{Z} \times \mathrm{Z}[P(1-P) /(\mathrm{D} \times \mathrm{D})]$. Where $\mathrm{Z}=1.96$ with confidence level of $95 \%$.Sample from different settings were selected randomly by Neyman's pick proportionate allocation method. This allocation method was used to maximize the survey precision by identifying the best sample for the stratums (six hospitals). We sent the questionnaire to 453 subjects to keep the RR of $70 \%$ in order to have desired sample size for final analysis.

A structured questionnaire of one A4-sized paper has been prepared containing demographical queries including age groups, gender, nationality, job category, and place of employment. It also had 15 closed-ended questions/ stems with five points Likert scaling starting from strongly disagree to strongly agree as $1-5$, reflecting the perception of physicians about EMRS. General Directorate of Health Affairs, Makkah region experts in Medical IT verified the content and face validity of the questionnaire.

Questionnaire stability, that is, internal consistency was measured by Cronbach's alpha using kappa statistics through Statistical Package for Social Sciences (SPSS) version 16 (SPSS Inc, Chicago, IL, USA). The Cronbach's alpha and Guttman split-half was shown for each stem. Ten percent of selected sample size was chosen and the subjects (physicians) were selected by randomization irrespective to their age, gender, nationality, and category from the identified settings. Out of the $10 \%$, the RR was $79 \%$. Test-retest reliability could not be measured because of impediments in arranging the subjects twice to fulfill the same questionnaire after a gap of certain time period.

In each enrolled hospital, a formal demonstration was given in order to explain the projects detail followed by questionnaire distribution to the selected subjects. Time of 2 weeks to answer the questionnaires was provided. The results were categorized as "positive" if percent of responses were rated 4 or 5 (agree/strongly agree), "neutral" if rated 3 , and negative if rated 1 or 2 (strongly disagree/disagree). Average rate for each stem as well as for subjects stratified into categories, gender, nationality, working place, and age groups were measured.

\section{Data analysis}

Descriptive data analysis techniques, that is, count, percentage, and average calculations, were implemented by using Microsoft Excel 2007 on personal computer.

\section{Ethical considerations}

Research project had been approved by General Directorate of Health Affairs, Makkah Region and all the participants were made aware of all the potential and future prospects of this survey. All respondents were assured of strict confidentiality of their identity.

\section{RESULTS}

RR of 356 was found to have margin of error of $4.7 \%$ with 95\% confidence level with total target population of 1,802. Only 317 surveys were selected based on the results of the sample size formula shown in the methods section. Majority of subjects were selected from H3 King Fahd Hospital, Jeddah $(83,26.3 \%)$ and H5 Alnoor Specialist Hospital, Makkah (77, 24.4\%). Overall questionnaire stability, that is, Cronbach's alpha and Guttman split-half coefficient weremeasured to be 0.86 and 0.79 , respectively. Physicians' residents $(147,46.4 \%)$, male $(200,63.1 \%)$, expatriates $(207$, $65 \%)$, and age group $36-45$ years $(133,42 \%)$ were dominant [Tables 1-3].

Regarding the positive perception, two stems, that is, Q5 and Q7 were appreciated by the majority, that is, "Computers are important for practicing of medicine" (77.7\%) with average rating (AR) of 4.1 and "EMRS improve quality of practice (work life)" (71.2\%, AR = 3.8). However, negative response was also found for the stems, but the 
Table I: Study settings and sample size allocation

\begin{tabular}{|c|c|}
\hline \multirow[t]{3}{*}{ Settings } & 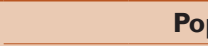 \\
\hline & C* \\
\hline & n (\%)** \\
\hline Alnoor Specialist Hospital, Makkah city H5 & $87(23.5)$ \\
\hline Hera General Hospital, Makkah city HI & $32(8.6)$ \\
\hline King Abdul Aziz Hospital, Ta'if city H2 & $75(20.2)$ \\
\hline King Fahd Hospital, Jeddah city H3 & I0I (27.2) \\
\hline Maternity and Child Health Hospital, Jeddah city H4 & $54(14.6)$ \\
\hline King Abdul Aziz Hospital, Jeddah city H6 & $22(5.9)$ \\
\hline Total & $37 \mid(20.5)$ \\
\hline \multicolumn{2}{|c|}{$\begin{array}{l}\text { C: Consultants, S: Specialists, R: Residents. *Percentages have been measured from each } \\
\text { allocated to each hospital by Neyman's pick proportionate allocation method, for exan }\end{array}$} \\
\hline \multicolumn{2}{|l|}{ Table 2: Subjects' demography $(n=3 \mid 7)$} \\
\hline Variables & $n(\%)$ \\
\hline \multicolumn{2}{|l|}{ Physicians category } \\
\hline Consultants & $66(28.8)$ \\
\hline Specialists & 104 (32.8) \\
\hline Residents & 147 (46.4) \\
\hline \multicolumn{2}{|l|}{ Gender } \\
\hline Male & $200(63.1)$ \\
\hline Female & 117 (36.9) \\
\hline \multicolumn{2}{|l|}{ Nationality } \\
\hline Saudi nationals & $110(35)$ \\
\hline Expatriates & $207(65)$ \\
\hline \multicolumn{2}{|l|}{ Age groups in years } \\
\hline$\leq 35$ & $82(26)$ \\
\hline $36-45$ & $133(42)$ \\
\hline $46-55$ & $67(2 \mathrm{I})$ \\
\hline $55-65$ & $35(\mathrm{II})$ \\
\hline
\end{tabular}

stem Q10 "It does not disrupt the workflow" was at the top of negative response $(35.1 \%, \mathrm{AR}=2.9)$ followed by Q6 "EMRS is comfortable while entering the data instead of writing" (34.8\%, AR = 2.9) [Figure 1].

Perception about EMRS was appreciated mostly by consultants $(53.9 \%, \mathrm{AR}=3.5)$, male $(53.4 \%, \mathrm{AR}=3.4)$, expatriates (56.7\%, AR $=3.5)$, physicians of $\mathrm{H} 2 \mathrm{King}$ Abdul Aziz Hospital Ta'if (56.9\%, AR = 3.5), and age group of $46-55$ years $(53.8 \%, A R=3.4)$ [Figure 2].

Overall perception of EMRS was found positive by $52.8 \%$, while $20.1 \%$ negatively responded.

\section{DISCUSSION}

In this study we found that nine (25\%) out of total 36 hospitals under $\mathrm{MOH}$ in the Makkah region have implemented EMRS that makes the level of EMRS uptake higher than that of the eastern province (15.8\%) found in a study with aims to determine the level and extent of usage of EMRS in government-related hospitals. We also found a difference in variety/types of EMRS in our study settings as compared to eastern province where all the study hospitals were using the same EMRS. ${ }^{[4]}$

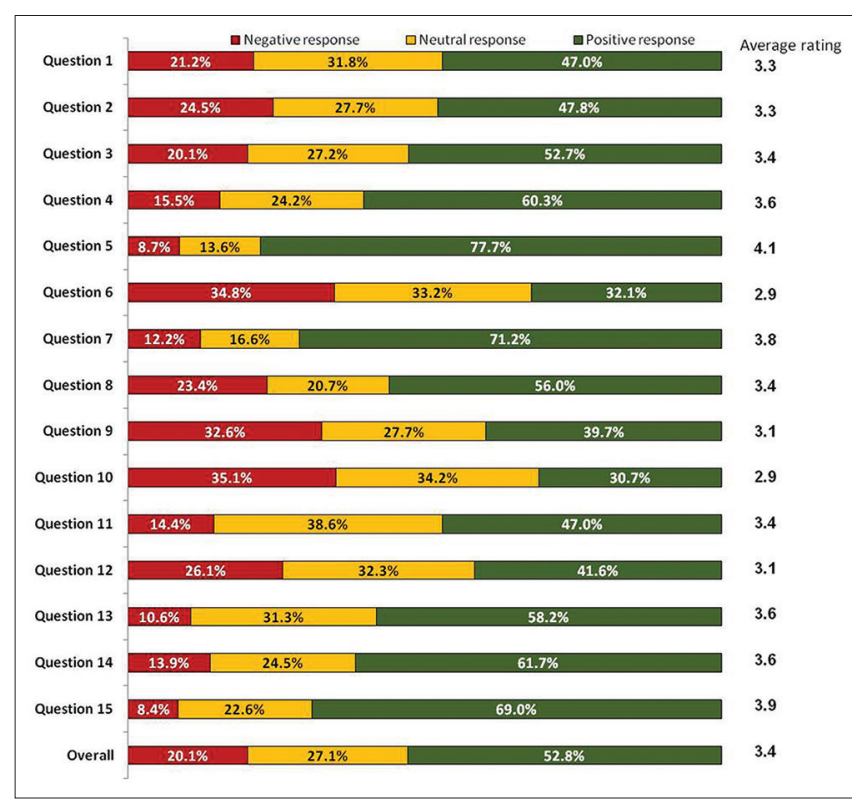

Figure 1: Subjects response to questions about electronic medical response system

Our study findings can be compared to a number of studies like; a cross-sectional survey including physicians to evaluate the knowledge, attitude, and practice of physicians towards the EMRS was conducted in Oman in 2011. EMRS as an effective tool in improving quality, performance, and timeliness was rated by $15.6 \%$ of physicians, while $29.4 \%$ of respondents considered it poor in worth. The majority $(67.4 \%)$ reported difficulty with their performance, while using the EMRS. The overall quality of work was perceived not to have changed mentioned by $41.2 \%$ of the respondents. The low satisfaction and underperformance was found to be associated with younger age and junior designation. ${ }^{[5]}$

Our survey stems reflected the physicians' point of view to the values and imperative benefits of EMRS in general. More than $50 \%$ of all physicians regardless the designation category, nationality, gender, age, and settings have given an overall positive perception about the EMRS. On the other hand, a tendency towards the facts that EMRS disrupts 


\begin{tabular}{|c|c|c|c|}
\hline $\begin{array}{l}\text { Serial } \\
\text { no. }\end{array}$ & Questions/stems & $\begin{array}{c}\text { Cronbach's } \\
\text { alpha }\end{array}$ & $\begin{array}{c}\text { Guttman } \\
\text { split-half } \\
\text { coefficient }\end{array}$ \\
\hline QI & I am generally satisfied with EMRS & 0.81 & 0.76 \\
\hline Q2 & EMRS is easy to use & 0.86 & 0.81 \\
\hline Q3 & $\begin{array}{l}\text { EMRS gives information which helps } \\
\text { you in better writing }\end{array}$ & 0.81 & 0.81 \\
\hline Q4 & $\begin{array}{l}\text { EMRS increases the comprehensiveness } \\
\text { of care which I provide }\end{array}$ & 0.83 & 0.83 \\
\hline Q5 & $\begin{array}{l}\text { Computers are important for } \\
\text { practicing of medicine }\end{array}$ & 0.85 & 0.8 \\
\hline Q6 & $\begin{array}{l}\text { EMRS is comfortable while entering } \\
\text { the data instead of writing }\end{array}$ & 0.87 & 0.82 \\
\hline Q7 & $\begin{array}{l}\text { EMRS improve quality of } \\
\text { practice (work life) }\end{array}$ & 0.81 & 0.76 \\
\hline Q8 & $\begin{array}{l}\text { EMRS increase practice } \\
\text { productivity (patients per day) }\end{array}$ & 0.83 & 0.81 \\
\hline Q9 & EMRS decrease the work load & 0.87 & 0.81 \\
\hline Q10 & It does not disrupt the workflow & 0.89 & 0.83 \\
\hline QII & $\begin{array}{l}\text { Benefits of EMRS outweigh the } \\
\text { inconveniences }\end{array}$ & 0.91 & 0.85 \\
\hline Q12 & $\begin{array}{l}\text { EMRS does not reduce the } \\
\text { communication among the users, i.e., } \\
\text { healthcare providers }\end{array}$ & 0.93 & 0.76 \\
\hline Q13 & $\begin{array}{l}\text { EMRS has a benefit of remote access } \\
\text { usage and ordering }\end{array}$ & 0.95 & 0.78 \\
\hline Q14 & $\begin{array}{l}\text { All the orders can be done in one } \\
\text { place by using EMRS }\end{array}$ & 0.89 & 0.72 \\
\hline Q15 & $\begin{array}{l}\text { Typed orders are clear to read leading } \\
\text { to less error }\end{array}$ & 0.86 & 0.81 \\
\hline \multicolumn{2}{|l|}{ Overall } & 0.86 & 0.79 \\
\hline
\end{tabular}

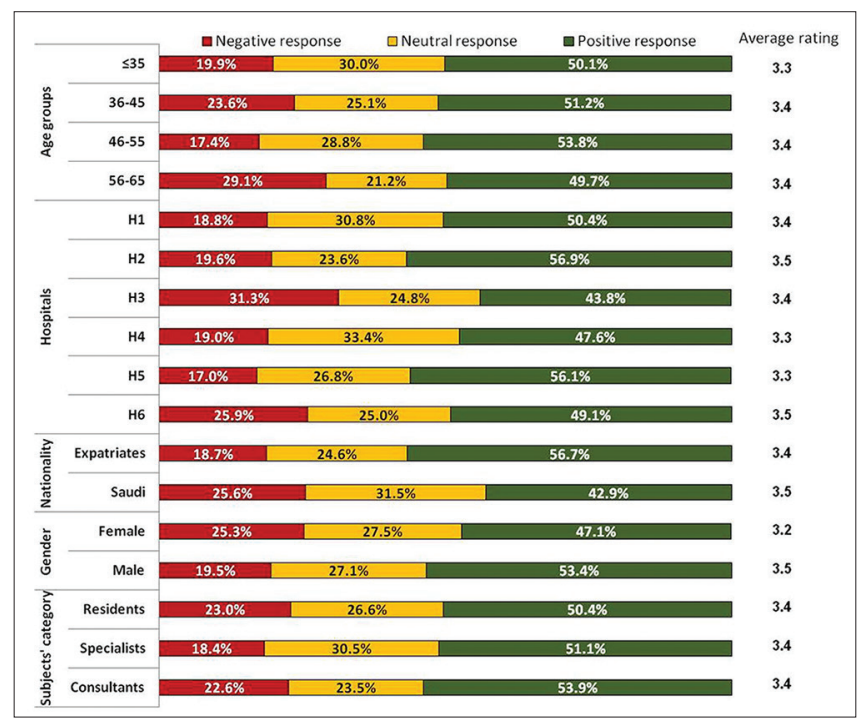

Figure 2: Subjects' overall response to questions about electronic medical record system stratified into their category, gender, nationality, hospitals, and age groups. H1 = Hera General Hospital (Makkah), H2 = King Abdul Aziz Hospital (Ta'if), H3 = King Fahd Hospital (Jeddah), H4 = Maternity and Child Health Hospital (Jeddah), $\mathrm{H} 5=$ Alnoor Specialist Hospital (Makkah), H6 = King Abdul Aziz Hospital (Jeddah)

the workflow consistent with the survey conducted on nurses in Turkey. ${ }^{[6]}$ It increases the work load, reduces the communication among users, and not comfortable while entering the data instead of writing had been seen. However, females, Saudi, and older age (56-65 years) had weakness in understanding the values and benefits of EMRS in our study. Nurses' perceptions about the electronic health recordin Spain also werefound positive in the context of its continuity of care and exchange information on patient health data. ${ }^{[7]}$

According to Bleich and Slack ${ }^{[8]}$ and Nour El Din ${ }^{[9]}$ excited acceptance of EMR by physicians and nurses is because of its easiness to use, but it was concluded in the eastern province of Saudi Arabia that benefits of the EMR are not fully achieved because of underutility of many core functions that can be improved by the EMR training and improvement of its key identified aspects.

Study by Darr et al., in 2003 suggested that the senior physicians had positive view about EMRS in the managerial role; however, junior physicians emphasized on its negative occupational effects on their work as found in our survey where perception of senior physicians were more positive. The nurses identified use of the EMR as good for quality care and administration of patient care. ${ }^{[10]}$

The study of Laerum et al., in 2001 revealed a low level of use of EMRS by physicians because of a lack of available computers and physicians' literacy using the computer. There was no significance difference between EMRS in terms of respondents' age, sex, or place of employment. ${ }^{[11]}$ Success of any information system depends upon the data quality and its completeness, end users computer literacy, and experience as well. User friendly EMRS is critical to facilitate the process. ${ }^{[12]}$

\section{CONCLUSION}

Survey outcomes show positive and negative impacts about EMRS at our settings. The study revealed that physicians are generally satisfied with EMRS, and they believe the system can improve quality of care for patients. EMRS is a good source of education and communication as well. Development of a good EMRS requires the fullest and sincere cooperation of all healthcare professionals; especially the medical staff, health information professionals, and information technologists. A future plan should address how to improve the system with continued upgrading. In addition, the cost associated with system upgrade and improvement must be addressed by the $\mathrm{MOH}$.

\section{Recommendations}

A further comparative usability evaluation study about different EMRSs by the end users in different settings of Makkah region is highly recommended. It is also recommended to evaluate the current status of perception about the EMRS in relation to the past efforts done by 
directorate general office in order to improve the perception as well as the comparison with the current study.

\section{REFERENCES}

1. Al-Otaibi FS. Towards an electronic health record in kingdom of Saudi Arabia. Paper presented at: Fourth regional conference on e-Health. 2005. (updated 2005). Available Online from: http://www.emro.who. int/his/ehealth/Presentations/Iran04/SaudiArabia.pps. [Last cited on 2009 Apr 13].

2. SAMIRAD [Home page on internet]. Saudi Arabia. Makkah region is most populated in Saudi Arabia. (updated 2009). Available from: http:// www.saudinf.com/main/y7733.htm [Last cited on 2009 Aug 29].

3. Alyemeni M. Five Year Program to Transform Healthcare Delivery in Saudi Arabia. Saudi Arabia $\mathrm{MOH}$ lpower point presentation on internet]. Available from: http://www.salud-e. $\mathrm{cl} / \mathrm{wps} / \mathrm{wcm} / \mathrm{connect} / 5 \mathrm{fd} 750 \mathrm{c} 2-349 \mathrm{f}-4 \mathrm{f3f}$-badd-1d8fdb0a5593/ saudi + arabia +e-health + strategy.pdf?MOD $=$ AJPERES and CACHEID $=5 f d 750 c 2-349 f-4 f 3 f-b a d d-1 d 8 f d b 0 a 5593$. [Last cited on 2013 Aug 01].

4. Bah S, Alharthi H, El Mahalli AA, Jabali A, Al-Qahtani M, Al-kahtani N. Annual survey on the level and extent of usage of electronic health records in government-related hospitals in Eastern Province, Saudi Arabia. Perspect Health Inf Manag 2011;8:1b.

5. Al-Mujaini A, Al-Farsi Y, Al-Maniri A, Ganesh A. Satisfaction and perceived quality of an electronic medical record system in a tertiary hospital in Oman. Oman Med J 2011;26:324-8.
6. Top M, Gider O. Nurses' views on electronic medical records (EMR) in Turkey: An analysis according to use, quality and user satisfaction. J Med Syst 2012;36:1979-88.

7. Galimany Masclans J, Garrido Aguilar E, Roca Roger M, Girbau García MR. New technologies and nursing. Use and perception of primary health care nurses about electronic health record. Rev Enferm 2012;35:42-5.

8. Bleich HL, Slack WV. Reflections on electronic medical records: When doctors will use them and when they will not. Int J Med Inform 2010;79:1-4

9. Nour El Din MM. Physicians' use of and attitudes toward electronic medical record system implemented at a teaching hospital in Saudi Arabia. J Egypt Public Health Assoc 2007;82:347-64.

10. Darr A, Harrison M, Shakked L, Shalom N. Physicians' and nurses' reactions to electronic medical records systems. J Health Organ Manage 2003;17:349-59.

11. Laerum H, Ellingsen G, Faxvaag A. Doctors' use of electronic medical records systems in hospital: Cross sectional survey. Br Med J 2001;323:1344-8.

12. Fraser HS, Biondich P, Moodley D, Choi S, Mamlin BW, Szolovits P. Implementing electronic medical record systems in developing countries. Inform Prim Care 2005;13:83-95.

Cite this article as: Shaker HA, Farooq MU, Dhafar KO. Physicians' perception about electronic medical record system in Makkah Region, Saudi Arabia. Avicenna J Med 2015;5:1-5.

Source of Support: Nil, Conflict of Interest: None declared. 